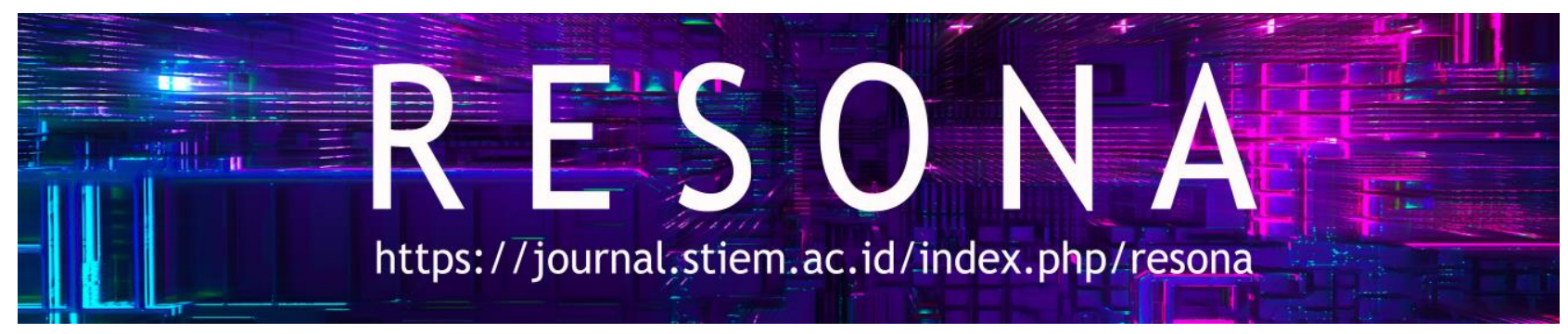

PENGUATAN USAHA UKM BENGKEL LAS MAESTRO MELALUI

IMPLEMENTASI TATA KELOLA MANAJERIAL BERBASIS POAC DI KELURAHAN MERJOSARI KOTA MALANG

\author{
Adya Hermawati ${ }^{1}$, Choirul Anam ${ }^{2}$, Survival ${ }^{2}$ \\ ${ }^{1}$ Program Pasca Sarjana Universitas Widyagama Malang \\ ${ }^{2}$ Fakultas Ekonomi Universitas Widyagama Malang
}

\section{INFO NASKAH}

Diserahkan

30 Sepetember 2020

Diterima

1 Desember 2020

Diterima dan Disetujui

29 Juni 2021

Kata Kunci:

UKM, Bengkel Las,

Manajerial dan

Keuangan, Siklus

Akuntansi, POAC

Keywords:

UKM, Welding

Workshop, Managerial

and Finance,

Accounting Cycle,

POAC.

\section{ABSTRAK}

Sebagai mitra, dalam PROPENMAS ini adalah Bengkel Las Maestro milik $M$ Basori yang berlokasi di Joyo Asri, RW 08 Kelurahan Merjosari, Kota Malang. Mengutamakan pemberdayaan tenaga kerja masyarakat setempat, Namun, teridentifikasi, perkembangan usahanya lambat dan kurang maksimal, perolehan profit belum maksimal dan belum sesuai target yang diharapan. Sistem pembinaan yang dilakukan untuk tenaga kerja selama ini masih dalam bentuk yang sederhana dari pemilik usaha. Sehingga, selama ini usaha Mitra dilakukan atas dasar pengetahuan dan keterampilan mandiri. Permasalahan berfokus pada aspek manajerial dan keuangan. Hal ini menjadikan UKM Bengkel Las Maestro sulit berkembang. Lemahnya aspek tatakelola administrasi dan keuangan, menjadikan pengelolaan aspek manajemen keuangan belum memenuhi standar keuangan usaha yang sehat. Hanya mencantumkan pesanan dan harga total dari pesanan, belum dilakukan pencatatan transaksi secara sistematis berstandar siklus akuntansi. Solusi yang ditawarkan kepada mitra adalah peningkatan pengetahuan UKM Bengkel Las Maestro di bidang manajemen organisasi dan manajemen keuangan dalam pengelolaan UKM, sehingga akan lebih meningkatkan produktivitas usahanya. Program ini dilakukan melalui pelatihan manajerial organisasi dan manajemen keuangan berstandar siklus akuntansi UKM dengan basis planning organizing actuating controling (POAC).

Abstract. As a partner, in this PROPENMAS is M Basori's Las Maestro Workshop which is located in Joyo Asri, RW 08 Merjosari Urban Village, Malang City. Prioritizing the empowerment of the community workforce, however, it has been identified, the development of the business is slow and not maximal, the profit is not maximized and is not yet according to the expected target So far, the guidance system implemented for the workforce is still in the simple form of the business owner. So that all this time Partner's efforts have been carried out on the basis of independent knowledge and skills. The problem focuses on managerial and financial aspects. This makes it difficult for the Las Maestro Workshop UKM to develop. Weak aspects of administrative and financial governance, management of financial management aspects have not met sound business finance standards. Only the order orders and the total price of the orders have not been recorded in a systematic manner with the accounting cycle standard. The solution offered to partners is to increase the knowledge of SME Workshop Las Maestro in the field of organizational management and financial management in SME management, so that it will increase business productivity. This program is carried out through training in organizational managerial and financial management standardized on the accounting cycle for SMEs on the basis of planning organizing actuating control (POAC). 


\section{PENDAHULUAN}

Usaha Kecil Menengah (UKM) merupakan jenis usaha berskala kecil. Menurut (UU No. 20 Tahun 2008, 2008) UKM merupakan usaha ekonomi produktif yang dimiliki oleh perorangan atau badan usaha yang memiliki kriteria aset sejumlah Rp50.000.000Rp500.000.000., untuk usaha kecil dan Rp500.000.000., hingga Rp10.000.000.000. UKM di Indonesia terbagi menjadi 4 kriteria yaitu livehood activities, micro enterprise, small dynamic enterprise dan fast moving enterprise.

Di Indonesia perkembangan UKM dalam beberapa tahun terakhir mengalami laju yang amat signifikan (Suci et al., 2017), menggambarkan pertumbuhan UMKM ini pada risetnya. Dalam penelitiannya, tercatat peningkatan usaha menengah sebesar $13.59 \%$. Tidak hanya itu, penelitian ini juga mencatat perkembangan usaha kecil sebesar 9.68\%. Hal ini menandakan bahwa UKM berperan sangat besar terhadap pertumbuhan ekonomi di Indonesia pada umumnya.

Salah satu hal yang juga turut andil dalam perkembangan UKM di Indonesia adalah pemanfaatan teknologi. Hal ini memudahkan para pelaku usaha untuk meluaskan usahanya melalui E-Commerce. Febriantoro (2018) dalam penelitiannya menjabarkan mengenai pemanfaatan information, communication and technology (ICT) bagi pelaku usaha. ICT yang diaptasi kedalam E-Commerce ini membuka peluang usaha yang baru serta dapat menjangkau konsumen yang lebih luas. Hal ini telah dilakukan oleh para pelaku usaha di seluruh Indonesia, salah satunya adalah di kota Malang yang saat ini terkenal dengan UKM pada sektor kuliner.

Kota Malang merupakan salah satu kota besar di Indonesia yang menjadi koblat untuk tren kuliner di Indonesia. Maka dari itu, tidak mengherankan pula jika dektor kuliner menjadi salah satu sektor UKM yang berkembang pesat. Agusetyaningrum et al., (2016) juga turut menyimpulkan dalam risetnya mengenai UKM dikota Malang yang berfokus pada bidang kuliner. Data menunjukkan bahwa sektor kuliner merupakan bidang yang paling mendominasi dan memiliki perkembangan paling pesat. Selain sektor kuliner, terdapat bidang-bidang lain yang turut berkembang pesat. Bidang-bidang UKM tersebut adalah bidang jasa, pertokoan, kerajinan tangan serta bidang perbengkelan.

Merjosari merupakan salah satu daerah di kota Malang yang menunjukkan tingkat perkembangan UKM. Kuantitas UKM di kelurahan Merjosari kota Malang, cukup berkontribusi pada sektor ekonomi kerakyatan meski jenisnya bervariatif hal ini terpotret pada data Tabel 1. berdasarkan data observasi pada dinas UMKM kota Malang. Varian UKM di Kelurahan Merjosari 2020 sangat mendukung RPJMD kota Malang Tahun 2018-2023. 
Berbagai varian UKM tersebut, berkontribusi sebagai capaian pemerataan ekonomi dengan indikator indikatornya menjadikan dampak positif untuk kesejahteraan masyarakat. Fitria, (2019) mengungkapkan bahwa sentra usaha kecil dapat menjadi salah satu cara untuk memberdayakan kerabat, tetangga, dan masyarakat sekitar yang pada akhirnya cara ini dapat meningkatkan kesehjateraan warga. Konsistensi untuk mengoptimalkan pemberdayaan pengembangan UKM maupun kelompok masyarakat pengembang ekonomi kerakyatan inilah yang menjadi nilai lebih kelurahan Merjosari kota Malang, dalam pemberdayakan masyarakat guna peningkatan taraf ekonomi masyarakat menuju masyarakat sejahtera mandiri.

Tabel 1. UKM di kelurahan Merjosari 2020

\begin{tabular}{|c|c|c|}
\hline NOMOR & BIDANG UKM & KUANTITAS \\
\hline 1. & Bidang kuliner makanan & $75 \mathrm{UKM}$ \\
\hline 2. & Bidang kuliner minuman & $50 \mathrm{UKM}$ \\
\hline 3. & Bidang jasa & $23 \mathrm{UKM}$ \\
\hline 4. & Bidang pertokoan dan lain lain & 94 UKM \\
\hline 5. & Bidang bengkel las & 47 UKM \\
\hline 6. & Bidang kerajinan & $34 \mathrm{UKM}$ \\
\hline \multicolumn{2}{|r|}{ Total } & 323 UKM \\
\hline
\end{tabular}

Sumber: data UKM kelurahan Merjosari diolah Adya (2020)

Tabel 1. mengungkapkan data UKM di kelurahan Merjosari menjadi efek proporsional antara aspek kontribusi capaian kinerja RPJMD kota Malang dengan kontribusi strategi pemberdayaan ekonomi masyarakat di kelurahan Merjosari, kota Malang. Faktualisasi atas hilirisasi dari hasil penelitian tim pada Hibah Ristek Dikti pada skim penelitian PDUPT pendanaan 3 tahun yaitu tahun 2018, 2019, dan 2020 dengan obyek penelitian UKM, menjadi salah satu aspek kontribusi perolehan untuk implementasikan kegiatan Program Pengabdian untuk Masyarakat atau PROPENMAS ini. Dari situasi analisis awal tersebut, maka Tim Pengusul program PROPENMAS ini, mencoba membantu memecahkan salah satu permasalahan dari UKM Bengkel Las yang ada di wilayah Kelurahan Merjosari Kota Malang. Dalam kegiatan pengabdian kepada masyarakat ini, peneliti bermitra dengan UKM Bengkel Las Maestro. Dasar pertimbangan penentuan UKM bengkel las sebagai mitra dalam program PROPENMAS ini, sebagai berikut: 
a. UKM bengkel las sebagai usaha yang potensi dan berprospek sangat menjanjikan untuk dikembangkan atas varian produk berbahan dasar besi dan logam.

b. UKM bengkel las, potensi pasarnya sangat berpeluang tinggi.

c. UKM bengkel las, dari aspek eksistensi industri terhadap lingkungan dan kontribusi kehidupan perekonomian masyarakat sekitarnya, cukup tinggi dan bisa diandalkan.

d. UKM bengkel las kususnya di Kelurahan Merjosari berprospek sebagai UKM potensial untuk dikembangkan teridentifikasi peluang capaian profit yang menjanjikan.

Bengkel Las Maestro milik M. Basori yang berlokasi di Joyo Asri, RW 08 Kelurahan Merjosari, kota Malang adalah mitra dalam PROPENMAS. Usahanya M Basori ini produksinya berbahan dasar besi dan logam. Mengutamakan pemberdayaan tenaga kerja masyarakat setempat, sehingga berkontribusi membantu dan meningkatkan perekonomian masyarakat yang terlibat. UKM Bengkel Las Maestro ini berdiri sejak tahun 2005 atau 15 tahun berjalan, namun teridentifikasi, perkembangan usahanya lambat dan kurang maksimal. Tenaga kerja UKM ini awal berdirinya hanya dibantu oleh sebanyak 4 (empat) orang tenaga kerja lulusan SMK. Namun dengan berjalannya waktu, UKM ini memiliki penambahan jumlah tenaga kerja, sebanyak 8 tenaga kerja lulusan SMK. Dengan Upah per hari rata rata Rp75.000., sampai Rp100.000,-. Terkait kapasitas produksi usaha, rata-rata membutuhkan sekitar $250 \mathrm{~kg} / \mathrm{besi}$ dan logam per hari, guna menyelesaikan pesanan dengan berbagai varian produk. Kuantitas pesanan cukup dinamis dan bervariasi, namun perolehan profit belum maksimal dan belum sesuai target yang diharapan.

Awal berdirinya UKM Bengkel Las Maestro, secara umum hanya memproduksi pintu pagar besi dengan berbagai variasi ukuran, bentuk dan motif yang dikehendaki oleh konsumen. Seiring dengan perkembangan teknologi dan kebutuhan masyarakat, maka varian produknya berkembang dalam berbagai macam produk. Varian produknya antara lain: kerajinan logam; seperti rolling door; pintu harmonika; kanopi; kursi; kerangka besi mainan out door untuk anakanak TK; pagar; bengkel las; dan fiber glass. Bahan dasar dibuat dari bahan besi, aluminium, galvanis, stainless steel, poly carbonat, dan fiber glass serta bahan tambahan untuk asesoris yang terbuat dari bahan besi cor, stainless steel, kuningan, besi, dan aluminium. Adapun harga produk UKM mitra Bengkel Las Maestro bervariasi tergantung dari jenis bahan dan model yang dikehendaki oleh konsumen. Contoh variasi harga produk dapat dilihat dalam Tabel 2. 
Tabel 2. Contoh Variasi Harga Produk UKM Bengkel Las Maestro

\begin{tabular}{|c|c|c|c|c|}
\hline No & Jenis Produk & Bahan & Model & $\begin{array}{l}\text { UKM Bengkel Las } \\
\text { Maestro } \\
\text { Harga per m2 (Rp) }\end{array}$ \\
\hline 1. & Rolling door & Aluminium & Standar & $750.000,-$ \\
\hline 2. & $\begin{array}{l}\text { Pintu } \\
\text { Harmonika }\end{array}$ & Plat eser & Standar & $950.000,-$ \\
\hline 3. & Pintu & $\begin{array}{l}\text { Pipa galvanis segi } \\
\text { empat }\end{array}$ & Minimalis & $600.000,-$ \\
\hline 4. & Pagar & $\begin{array}{l}\text { Pipa galvanis segi } \\
\text { empat }\end{array}$ & $\begin{array}{l}\text { Sederhana asesoris } \\
\text { besi cor }\end{array}$ & $450.000,-$ \\
\hline 5. & Pagar & $\begin{array}{l}\text { Besi kotak dan } \\
\text { virkan }\end{array}$ & $\begin{array}{l}\text { Besi kotak dengan } \\
\text { asesoris besi virkan } \\
\text { yang dibentuk bunga }\end{array}$ & $550.000,-$ \\
\hline 6. & Kanopi & $\begin{array}{l}\text { Kerangka besi } \\
\text { kotak }\end{array}$ & Minimalis & 400.000 \\
\hline
\end{tabular}

Sumber: Data Sekunder diolah Adya (2020)
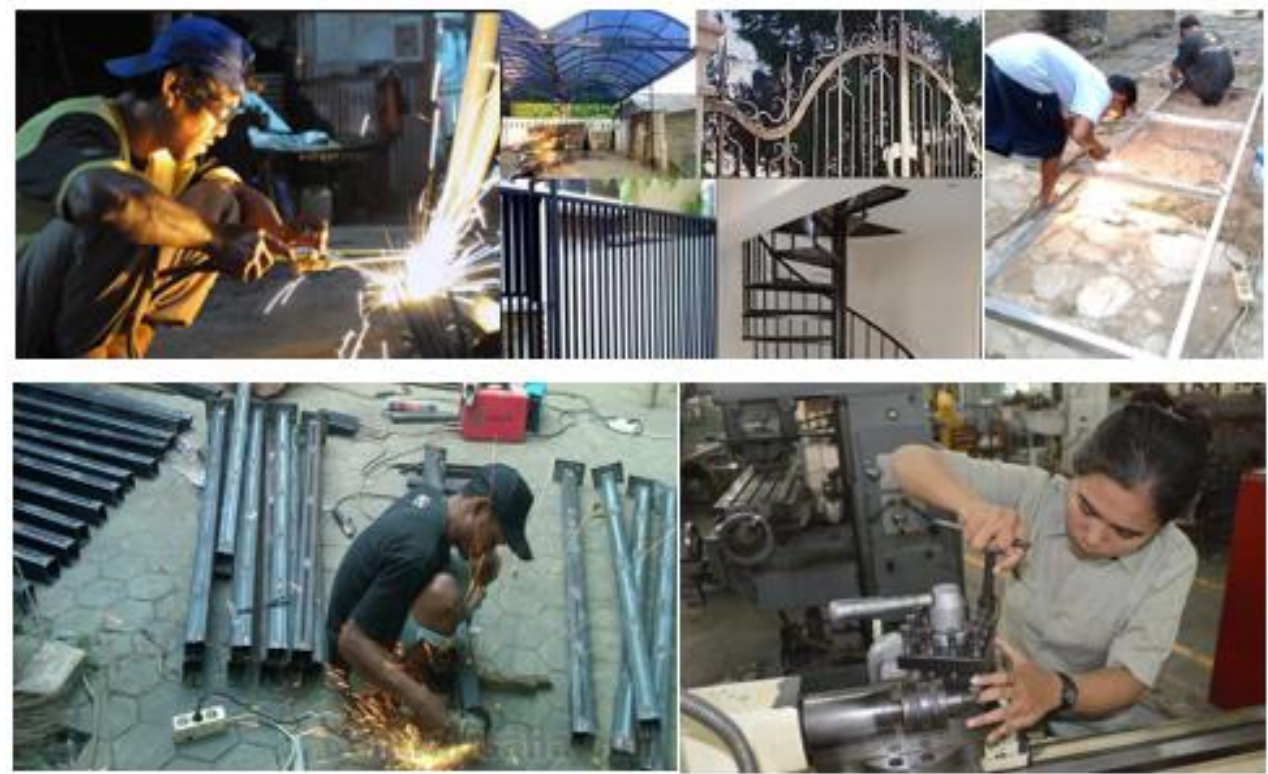

Gambar 1. Kegiatan Produksi dan Contah Hasil Produksi UKM Bengkel Las Maestro 


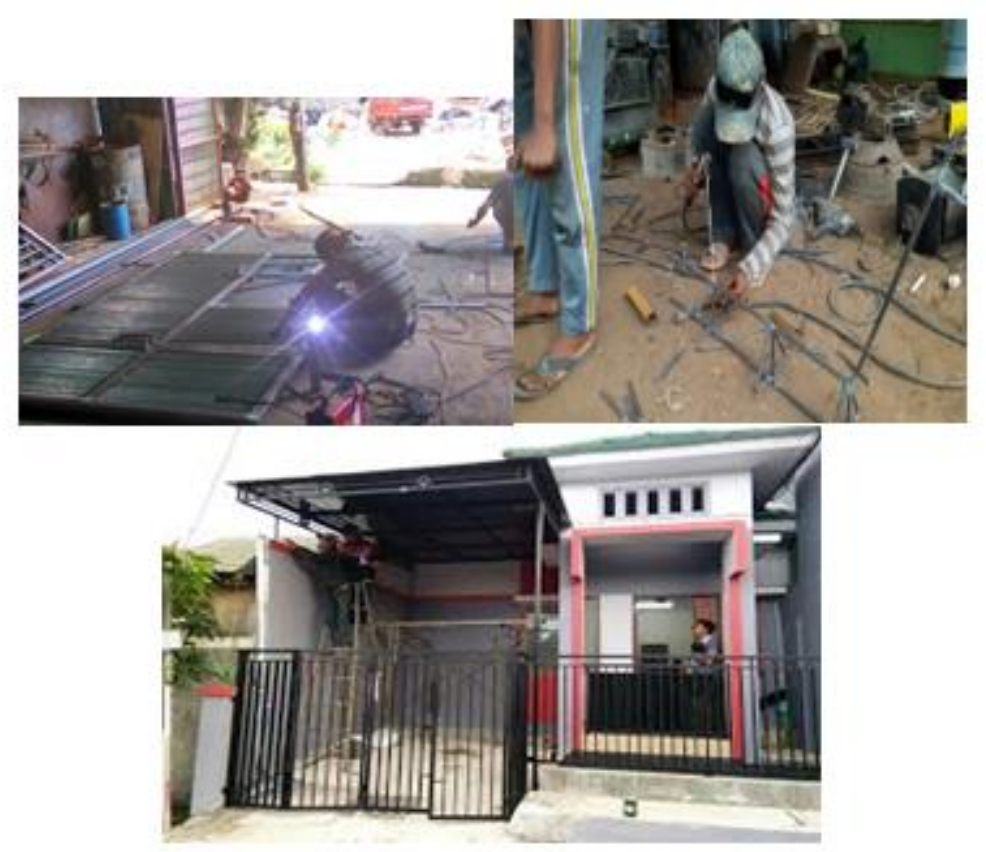

Gambar 2. Hasil Produksi UKM Bengkel Las Maestro

UKM Bengkel Las Maestro, tingkat pendidikan pemiliknya dan tenaga kerjanya, rata-rata lulusan SMK/sederajat. Pemberdayaan tenaga kerjanya, masih memberdayakan prioritas untuk masyarakat sekitarnya. Sistem pembinaan yang dilakukan untuk tenaga kerja selama ini masih dalam bentuk yang sederhana dari pemilik usaha. Mereka dididik dan dilatih secara bertahap dalam menggunakan alat dan cara kerjanya. Selama ini pihak pemerintah belum pernah mengadakan pelatihan dan pembinaan kepada pengembangan usaha Mitra, sehingga selama ini usaha Mitra dilakukan atas dasar pengetahuan dan keterampilan mandiri.

Permasalahan UKM Bengkel Las Maestro pada dasarnya beragam. Namun pada Propenmas ini, tim memetakan fenomena berfokus pada aspek manajemen. Lebih lanjut dari masalah aspek manajemen, teridentifikasi permasalahan yang dihadapi UKM Bengkel Las Maestro, adalah tatakelola manajerial yang dilakukan masih tidak terstruktur. Adalah belum tertatanya manajemen organisasi secara umum, yang semestinya bersandar pada planning organizing actuating controling (POAC). Kondisi faktual, pemilik Bengkel Las Maestro, masih berperan multifungsi. Multifungsi yang dimaksud yaitu: pemilik UKM Bengkel Las Maestro sebagai pengelola, merangkap keuangan, produksi, dan pemasaran. Hilirnya terjadi in_konsistensi dalam tatakelola organisasi. Sehingga dampaknya, UKM Bengkel Las Maestro perkembangannya tidak maksimal, dan capaian target belum sesuai seperti yang diharapkan. Hal ini menjadi faktor kendala, sehingga butuh adanya solusi. 
Sementara, pada tataran aspek keuangan, kondisi riil di UKM Bengkel Las Maestro, tatakelola administrasi dan manajemen keuangan masih belum baik. Pengelolaan keuangan belum bersandar pada planning organizing actuating controling (POAC). Hal ini dikarenakan production budget belum ada, cash flow finance ratio belum diterapkan, hanya mencatat secara global pesanan dan harga total dari pesanan. Belum dilakukan pencatatan periodik untuk aspek biaya terkait proses produksi (biaya bahan pembantu, biaya bahan baku, biaya tenaga kerja langsung, biaya tenaga kerja tidak langsung, harga pokok produksi, dan harga pokok penjualan). Sehingga, belum dapat diindentifikasi income statemen dalam keuangan berupa laba bersih tersistematis yang mestinya menjadi perolehan pemilik UKM secara periodik.

\section{MASALAH}

Dari analisis situasi diperoleh beberapa permasalahan UKM Bengkel Las Maestro, sebagai berikut:

a. Tatakelola manajerial organisasi UKM Bengkel Las Maestro tidak terstruktur dan belum bersandar pada planning, organizational, actuating, controling (POAC). Hal ini menjadikan UKM Bengkel Las Maestro sulit berkembang.

b. Lemahnya aspek tatakelola administrasi dan manajemen keuangan. Pengelolaan keuangan belum bersandar pada planning organizing actuating controling (POAC), sehingga pengelolaan manajemen keuangan belum memenuhi standar keuangan usaha yang sehat. Hal ini dikarenakan keuangan yang ada pada UKM tersebut hanya mencantumkan pesanan dan harga total dari pesanan, belum dilakukan pencatatan transaksi secara sistematis berstandart siklus akuntansi.

\section{METODE}

\section{Metode Pelaksanaan}

Langkah-langkah dalam menyelesaikan permasalahan bidang manajemen dan keuangan pada mitra UKM, sebagai berikut:

a. Koordinasi dan diskusi dengan mitra UKM tentang program dan jadwal program penyelesaian masalah bidang manajerial organisasi maupun bidang manajemen keuangan.

b. Pelatihan manajerial organisasi UKM berbasis POAC.

c. Pelatihan pengelolaan keuangan tersistematis berstandart siklus akuntansi UKM berbasis POAC. 
d. Di susun modul terkait manajerial organisasi dan manajemen keuangan tersistematis berstandar siklus akutansi UKM berbasis POAC.

e. Evaluasi program penyelesaian permasalahan bidang manajerial organisasi dan manajemen keuangan tersistematis berstandart siklus akuntansi pada mitra UKM.

\section{Metode Pendekatan}

Metode pendekatan untuk penyelesaian permasalahan bidang manajemen pada mitra UKM. Langkah pendekatan yang dilakukan adalah dengan cara melakukan koordinasi serta diskusi antara tim pengusul dan mitra UKM. Dari koordinasi dan diskusi yang dilakukan, maka dihasilkan 3 program strategis penyelesaian permasalahan bidang manajemen yaitu:

a. Pelatihan Manajerial Organisasi berbasis POAC

Pelatihan ini dilakukan untuk memberikan pengetahuan tentang manajemen organisasi berbasis UKM, sehingga mitra UKM akan lebih berkembang dengan manajemen organisasi UKM yang baik.

b. Pelatihan Pengelolaan Keuangan tersistematis berstandar siklus akuntansi UKM Berbasis POAC.

Pelatihan ini dilakukan untuk memberikan pengetahuan tentang sistem pengelolaan keuangan UKM berbasis POAC dengan standar akuntansi yang baik dan benar, sehingga mitra UKM akan lebih baik dalam pengelolaan keuangan dan akan lebih meningkatkan permodalan mitra UKM dalam menjalankan usahanya.

c. Evaluasi program bidang manajemen

Evaluasi ini dilakukan untuk melihat progress kemajuan dari sistem manajemen yang telah dilakukan perbaikan terhadap pengelolaan manajerial organisasi dan pengelolaan keuangan berdasar standar siklus akuntansi yang berbasis POAC pada UKM.

\section{HASIL DAN PEMBAHASAN}

Dari permasalahan yang telah diidentifikasi oleh tim, maka solusi yang ditawarkan kepada mitra adalah peningkatan pengetahuan UKM Bengkel Las Maestro dalam bidang manajemen organisasi dan manajemen keuangan dalam pengelolaan UKM, sehingga akan lebih meningkatkan produktifitas usahanya. Program ini dilakukan melalui pelatihan manajerial organisasi dan manajemen keuangan teristematis berstandar siklus akuntansi UKM berbasis planning organizing actuating controling (POAC). Gambaran iptek yang akan diterapkan ke mitra, antara lain: 1) Pelatihan manajerial organisasi UKM berbasis POAC; 2) Pelatihan pengelolaan keuangan tersistematis berstandar siklus akuntansi UKM berbasis POAC; dan 3) 
Modul pelatihan manajerial organisasi dan manajemen keuangan tersistematis berstandar siklus akutansi UKM berbasis POAC. Uraian penerapan: Planning yang akan diterapkan pada Bengkel Las Meastro adalah membuat rencana pencatatan scedul kegiatan, rencana anggaran dan rencana pengeluaran keuangan. Organizational yang akan diterapkan pada Bengkel Las Maestro adalah mengedukasi masing-masing staf agar penempatannya sesuai dengan soft skill dan hard skillnya. Actuating yang akan diterapkan pada Bengkel Las Maestro adalah membuat SOP setiap bagian guna mengetahui tupoksi yang dikerjakan, dan SOP standar pembukuan keuangan, dan Controlling yang akan diterapkan pada Bengkel Las Maestro adalah pengawasan berdasar SOP yang disusun, untuk setiap pekerjaan staf agar kinerja baik, serta memberikan arahan apabila terdapat kendala saat proses pengelasan bagi yang kesulitan dalam mengoperasikan alat Las. Contoh format anggaran untuk pencatatan jadwal kegiatan, rencana anggaran dan rencana pengeluaran keuangan, sebagai berikut:

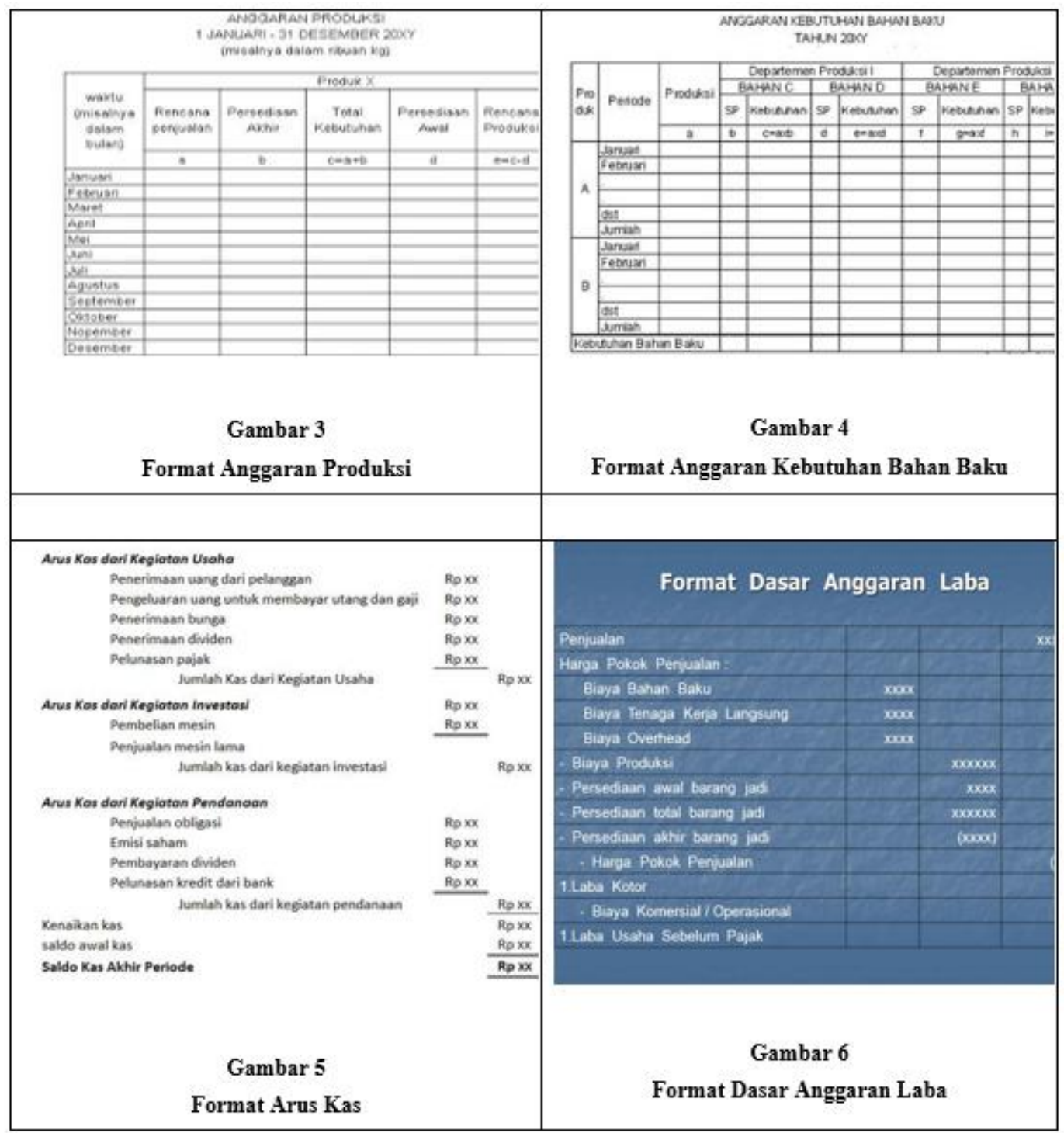


Format SOP pengelasan

\section{STANDAR OPERASIONAL PROSEDUR} Pengelasan SMAW (Shield Metal Arc Welding)

1. Nama Pekerjaan :

Pengelasan SMAW (Shield Metal Arc Welding)

2. Tujuan Pekerjaan :

Untuk menggabungkan dua material logam dengan cara dicairkan menggunakan panas yang berasal dari kawat elektroda yang telah dialiri listrik.

3. Prosedur Pekerjaan :

1.1 Langkah Pekerjaan:

1. Menyiapkan material yang akan digabungkan, alat-alat kerja, serta alat keselamatan dalam pekerjaan las.

2. Memasang elektroda pada kutub positif atau negative pada mesin las SMAW.

3. Men-setting mesin las SMAW (arus 75, 85, dan 95 A dan tegangan 220V)

4. Melakukan pengelasan sesuai garis pada pelat, atau alur dalam pekerjaan.

5. Membuang sisa terak pada hasil pengelasan dengan menggunakan palu terak.

6. Cek hasil pengelasan apakah sudah sesuai, apabila sesuai lanjutkan ke penghalusan hasil pengelasan, dan apabila belum sesuai ulangi kembali setting pada mesin las dan pengerjaan ulang pengelasan.

7. Melakukan penghalusan pada hasil pengelasan menggunakan gerinda, dengan catatan tidak sampai merusak hasil pengelasan.

8. Membersihkan kembali area kerja dari terak dan kotoran lain akibat pekerjaan pengelasan.

9. Merapikan dan menyimpan kembali alat-alat yang digunakan dalam melakukan pengelasan.

Format SOP pemesanan produk

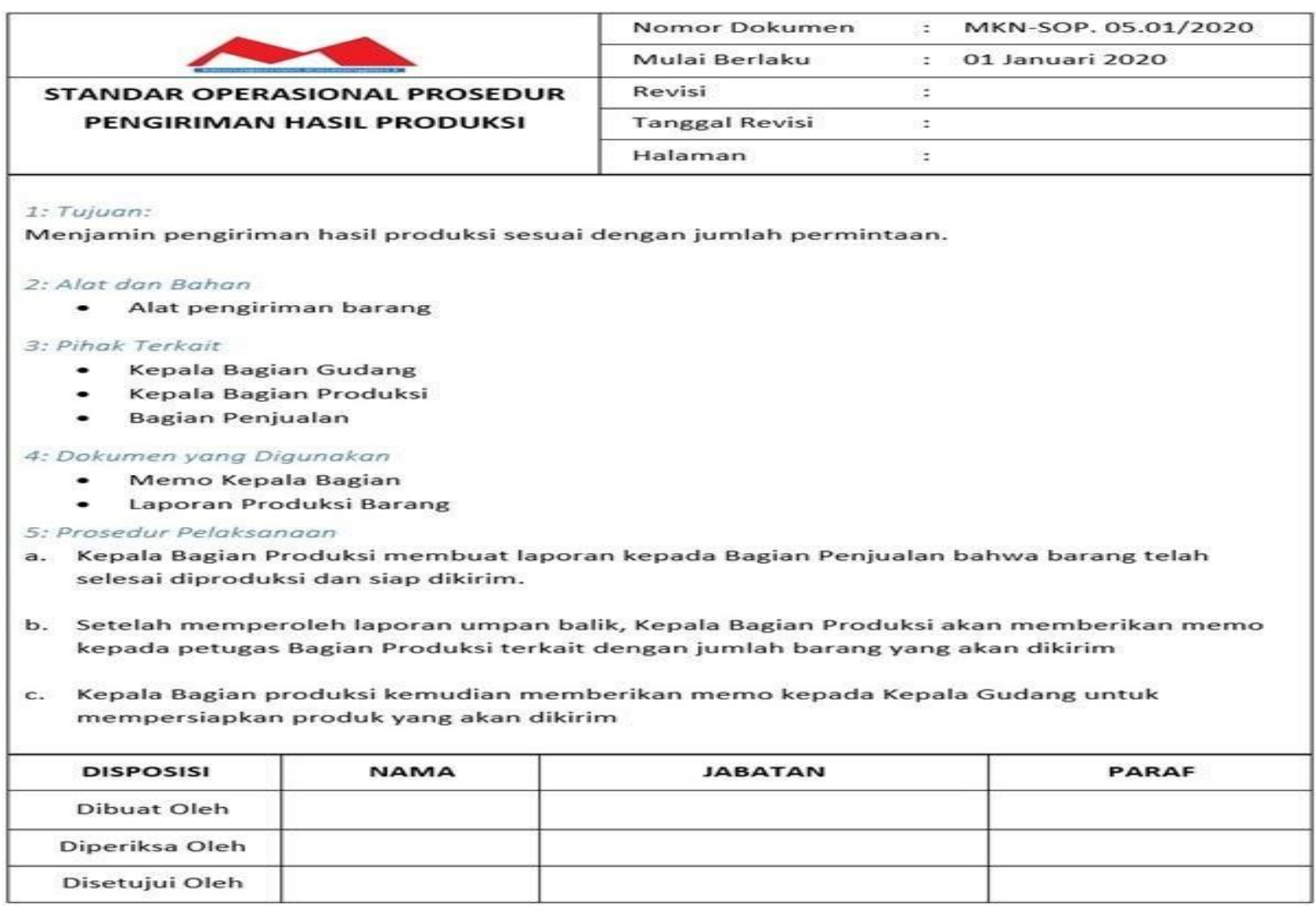




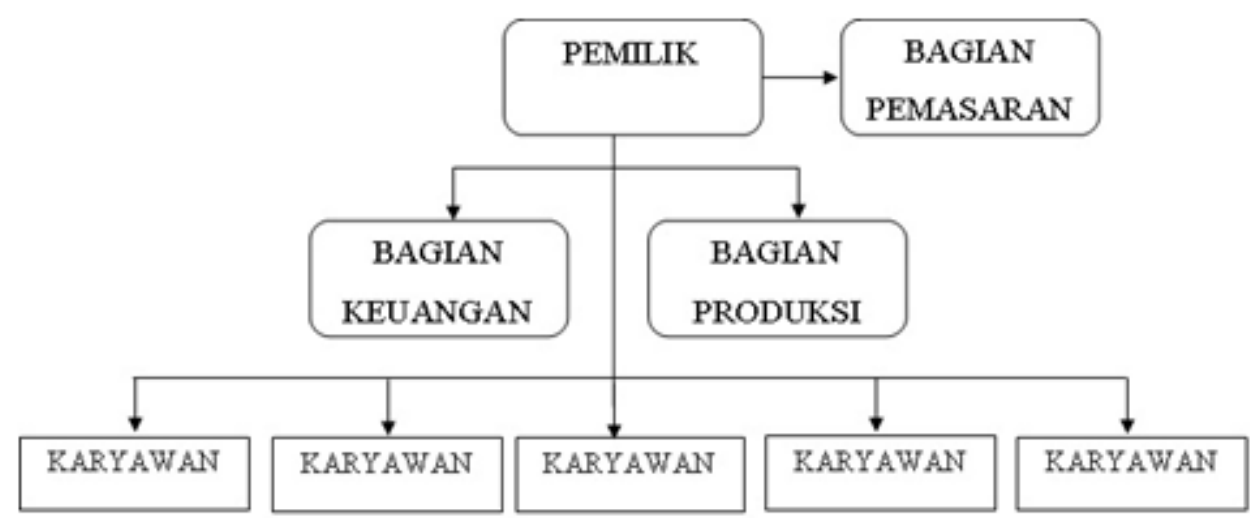

\section{SIMPULAN}

Berdasarkan dari hasil yang telah dilaksanakan terdapat beberapa simpulan. Pertama tatakelola manajerial organisasi di UKM bengkel Las Maestro sangatlah penting agar dapat bersaing dengan pesaing lainnya. Kedua, tatakelola pada administrasi dan manajemen keuangan harus ditingkatkan mengingat pengelolaan administrasi dan manajemen keuangan dapat dijadikan rujukan kesuksesan dari sebuah UKM. Jika UKM bengkel Las Maestro memiliki omset yang tinggi apabila melihat dari pencatatan pembukuan. Saran, guna membangun dan meningkatkan atau mengoptimalkan tatakelola tersebut, pemilik harus rutin melakukan pengecekan secara berkala kegiatan produksi dari input menjadi output sehingga dapat membuahkan hasil yang optimal.

\section{DAFTAR PUSTAKA}

Aisyah, Siti. 2019. Manajerial UKM. Aspek Pengembangan UKM dan UMKM. Jakarta: Insan Pres.

Agusetyaningrum, V., Mawardi, M., Pangestuti, E., 2016. STRATEGI PENGEMBANGAN USAHA KECIL DAN MENENGAH (UKM) UNTUK MENINGKATKAN CITRA KOTA MALANG SEBAGAI DESTINASI WISATA KULINER (Studi Pada Ukm Berbasis Kuliner Kota Malang). J. Adm. Bisnis S1 Univ. Brawijaya 38: 105-111.

Drucker P.E. 1985. Innovation and Enterpreneurship. New York: McGraw Hill Book. Grasindo

Febriantoro, W., 2018. Kajian dan Strategi Pendukung Perkembangan E-Commerce Bagi $\begin{array}{llllll}\text { Umkm Di Indonesia. J. MANAJERIAL } & 17,\end{array}$ https://doi.org/10.17509/manajerial.v17i2.10441

Fitria, H.A., 2019. Analisis Dampak Usaha Mikro Kecil Dan Menengah (UMKM) terhadap 
Kesejahteraan Masyarakat (Studi Pada Sentra Industri Kecil Roti Desa Kalimalang Kecamatan Sukorejo Kabupaten Ponorogo).

Hartono. Bandriyo. 2019. Administrasi Keuangan Usaha Mikro dan Usaha Makro.

Helmy, Djawahir Achmad. 2016. Manajemen Bisnis. Makalah Pelatihan UMKM. Malang: Klinik Bisnis UMKM FEB UB.

https://centrausaha.com/bengkel-las-sukses/

https://shopee.co.id/Pagar-besi-pagar-besi-minimalis-jasa-las-jasa-pengelasani. 98230486.1734670673

https://www.banguncipta.com/bengkel-las/

Panduan Program Pengabdian untuk Masyarakat. 2020. Malang: Universitas Widyagama Malang.

Suci, Y.R., Tinggi, S., Ekonomi, I., 2017. Perkembangan UMKM (Usaha Mikro Kecil Menengah) di Indonesia. J. Ilm. Fak. Ekon. 6, 51-58.

UU No. 20 Tahun 2008, 2008. UU No. 20 Tahun 2008. UU No. 20 Tahun 2008 1-31. 